\title{
New species of Meromyza from Palaearctic and Oriental China (Diptera: Chloropidae)
}

\author{
Shuwen An \& Ding Yang*
}

\begin{abstract}
An, S. \& Yang, D. 2009: New species of Meromyza from Palaearctic and Oriental China (Diptera: Chloropidae). — Entomol. Fennica 20: 94-99.

Two new Palaearctic species, Meromyza yangi sp. n. and M. zhuae sp. n., and one new Oriental species, M. wuyishanensis sp. n., are described. An updated key to the known species of the genus from China is presented.
\end{abstract}

S. An \& D. Yang, Department of Entomology, China Agricultural University, Haidian, Beijing 100094, China; *Corresponding author's E-mail: dyangcau @yahoo.com.cn

Received 29 August 2007, accepted 28 February 2008

\section{Introduction}

The genus Meromyza Meigen belongs to the subfamily Chloropinae (Andersson 1977). It can be easily recognized by the typically yellow body with 3 brownish to black or bicolor stripes on the mesonotum, the hind femur distinctly thickened with 2 rows of small black ventral warts, and the hind tibia correspondingly curved with the femur. The members of the genus Meromyza always are associated with gramineous plants. Several species attack cereal crops.

There are 93 species known from the world, of which 65 species are distributed in the Palaearctic Realm (Kanmiya 1983, Nartshuk 1984, 1992, 1994), 23 species in the Nearctic (Sabrosky 1987), 3 species in the Neotropical (Sabrosky 1984), and 1 species in the Afrotropical (Sabrosky 1980). Till now only 1 species of Meromyza has been reported from the Oriental Realm (Sichuan, China).

Up to now, 10 species are known to occur in China (An \& Yang 2005a, b). In this paper, 3 species are described as new to science. An updated key to the species from China is presented. The materials are deposited in the Entomological Mu- seum of China Agricultural University (CAU), Beijing.

\section{Updated Key to Species of Meromyza from China}

1. Palpus entirely yellow 2

- Palpus infuscated on apical half or entirely black

7

2. Three stripes on mesonotum connected with brownish; scutellum entirely brownish congruens An \& Yang

- Three stripes on mesonotum completely separated; scutellum yellow with a dark stripe or not

3. Stripes on mesonotum entirely black, median stripe extending to scutellum 4

- Stripes on mesonotum bicolor, median stripe extending to scutellum or not 5

4. Gonite stout; katepimeron with a black spot gansuensis An \& Yang

- Gonite curved apically; katepimeron without any spot zhuae sp.n.

5. Epandrium with long bristles

- Epandrium without long bristles; median 


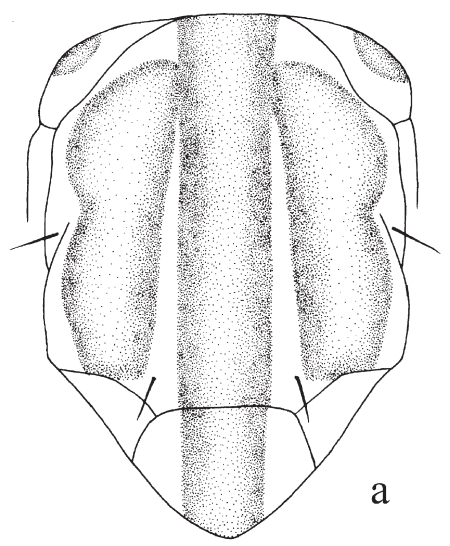

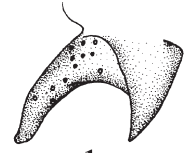

b
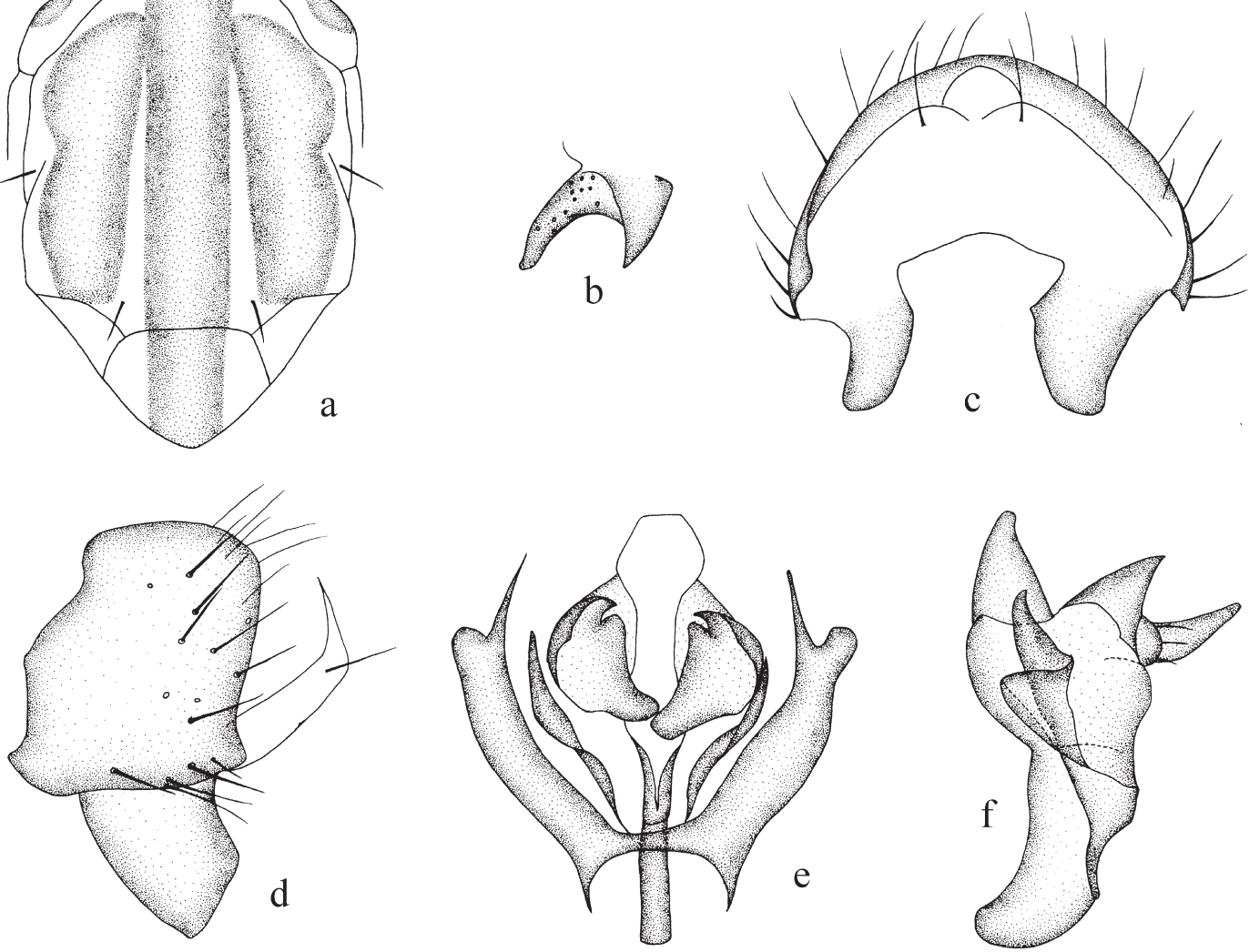

Fig. 1. Meromyza wuyishanensis sp. n., male. - a. Mesonotum, dorsal view. - b. Gonite, lateral view. - c. Epandrium, posterior view. - d. Epandrium, lateral view. - e. Hypandrium and phallic complex, ventral view. - f. Hypandrium and phallic complex, lateral view.

stripe on mesonotum bicolor and extending to scutellum yangisp.n.

6. Median stripe on mesonotum extending to scutellum neimengensis An \& Yang

- Median stripe on mesonotum not extending to scutellum; scutellum yellow with a brown spot

pratotum Meigen

7. Occiput black

- Occiput yellow or brown

8. Ocellar triangle and occiput entirely black; thorax and abdomen mostly black

nigripes Duda

- Ocellar triangle brown with black lateral margin; occiput black; thorax brown with black stripes, abdomen black with yellow posterior margin wuyishanensis sp. $\mathrm{n}$.

9. Postnotum brown or yellow with black spot

- Postnotum entirely black nigrofasciata Hendel
10. Stripes on mesonotum entirely black saltatrix (Linnaeus)

- Stripes on mesonotum brown or bicolor 11

11. Median stripe on mesonotum extending to scutellum nigriventris Macquart

- Median stripe on mesonotum not extending to scutellum, scutellum with spot

12

12. Gonite rounded apically ningxiaensis An \& Yang

- Gonite acute apically acutata An \& Yang

\section{Taxonomy}

\subsection{Meromyza wuyishanensis sp. n. (Fig. 1)}

Material examined. Holotype ${ }^{\lambda}$ : Fujian: Wuyishan, Huangganshan, 10.V.2004, Leg. Junhua Zhang. Paratypes 13 $\widehat{\partial} 6$ 우, same data as holotype. 
Diagnosis. Head brown with black occiput. Mesonotum brown with three entirely black stripes, which are confused anteriorly. Anterior gonite distinctly curved, posterior gonite triangular.

Description. Male. Body length 3.8-4.5 mm, wing length 3.1-3.9 mm.

Head brownish yellow with pale pollen, about 1.4 times as wide as long, and 1.1 times as wide as mesonotum; ocellar triangle yellow with black lateral margin and ocellar tubercle; occiput black; face without any spot. Hairs and bristles on head black except gena with pale hairs; in profile, head 0.9 times as long as high; gena as wide as third antennal segment; frons not distinctly produced beyond eye by about 0.14 times as long as long axis of eye. Antenna brownish with pale pollen and black dorsal surface; third antennal segment 1.1 times as long as wide; arista blackish. Hairs on antenna pale. Proboscis brown with pale hairs; palpus black with pale hairs.

Thorax (Fig. 1a) brown with pale pollen. Postpronotum with a black spot. Mesonotum 1.2 times as long as wide, with 3 black stripes, which are connected anteriorly; median stripe extending to scutellum; thoracic pleuron yellow, with a black spot each on anepisternum, katepimeron and katepisternum; scutellum brown with a black median stripe. Hairs and bristles on thorax black, but katepisternum with some long pale hairs. Wing hyaline, about 2.8 times as long as wide; veins brownish; relative length of costal section 2nd: 3rd: 4th as 3.5: 3: 3. Halter pale. Legs yellow with pale pollen, tarsi blackish. Hind femur 0.4 times as wide as long, and 2.0 times as wide as fore femur. Hairs on legs pale, bristles black.

Abdomen black on dorsum, each tergite with a yellow posterior margin; venter yellow. Hairs on abdomen chiefly pale.

Male genitalia (Fig. 1b-f). Epandrium yellow; surstylus black apically; gonite black, anterior gonite curved and posterior gonite triangular.

Female. Body length $4.5-4.8 \mathrm{~mm}$, wing length 3.0-3.6 mm.

Distribution. China (Fujian), Oriental Realm.

Remarks. The new species is similar to Meromyza sibirica Fedoseeva, 1961 in the distinctly curved anterior gonite and triangular posterior gonite, but can be separated from the latter by the entirely black median stripe on the mesonotum extending to the scutellum and short surstylus; in $M$. sibirica, the median stripe on the mesonotum extends slightly beyond the middle of the mesonotum, and the surstylus is long, about 1.7 times as long as wide (Kanmiya 1978).

Etymology. The specific is named after the locality Wuyishan.

\subsection{Meromyza yangi sp. n. (Fig. 2)}

Material examined. Holotype $\widehat{\jmath}$ : Inner Mongolia: Xilin Gol Meng, 15.VIII.1978, Leg. JikunYang.

Diagnosis. Palpus pale. Median stripe on mesonotum brown and black, extending to scutellum. Thoracic pleuron yellow, without any spots. Gonite black and stout, posterior gonite attached to posterior portion of anterior gonite.

Description. Male. Body length $4.1 \mathrm{~mm}$, wing length $3.0 \mathrm{~mm}$.

Head yellow with pale pollen, about 1.2 times as wide as long, and 1.2 times as wide as mesonotum; ocellar triangle yellow with black ocellar tubercle; occiput and face without any spot. Hairs and bristles on head black except gena with pale hairs; in profile, head 1.1 times as long as high; gena 1.2 times as wide as third antennal segment; frons not distinctly produced beyond eye by about 0.4 times as long as long axis of eye. Antenna brown with pale pollen; third antennal segment dark brown on dorsal surface, and 1.1 times as long as wide; arista blackish brown with brown basal segment. Hairs on antenna pale. Proboscis brown with pale hairs; palpus pale with pale hairs.

Thorax (Fig. 2a) yellow with pale pollen. Postpronotum with a small brown spot. Mesonotum 1.2 times as long as wide, with 3 black and brown stripes, median stripe brown on middle portion, extending to scutellum; thoracic pleuron yellow, without any spots; scutellum yellow with a black median stripe. Hairs and bristles on thorax black, but katepisternum with some long pale hairs. Wing hyaline, about 2.7 times as long as wide; veins brownish; relative length of costal section 2nd: 3 rd: 4 th as 3: 2.7: 3.1. Halter yellow. Legs yellow with pale pollen, coxae brown. Hind femur 0.3 times as wide as long, and 1.6 times as wide as fore femur. Hairs and bristles on legs black and pale. 

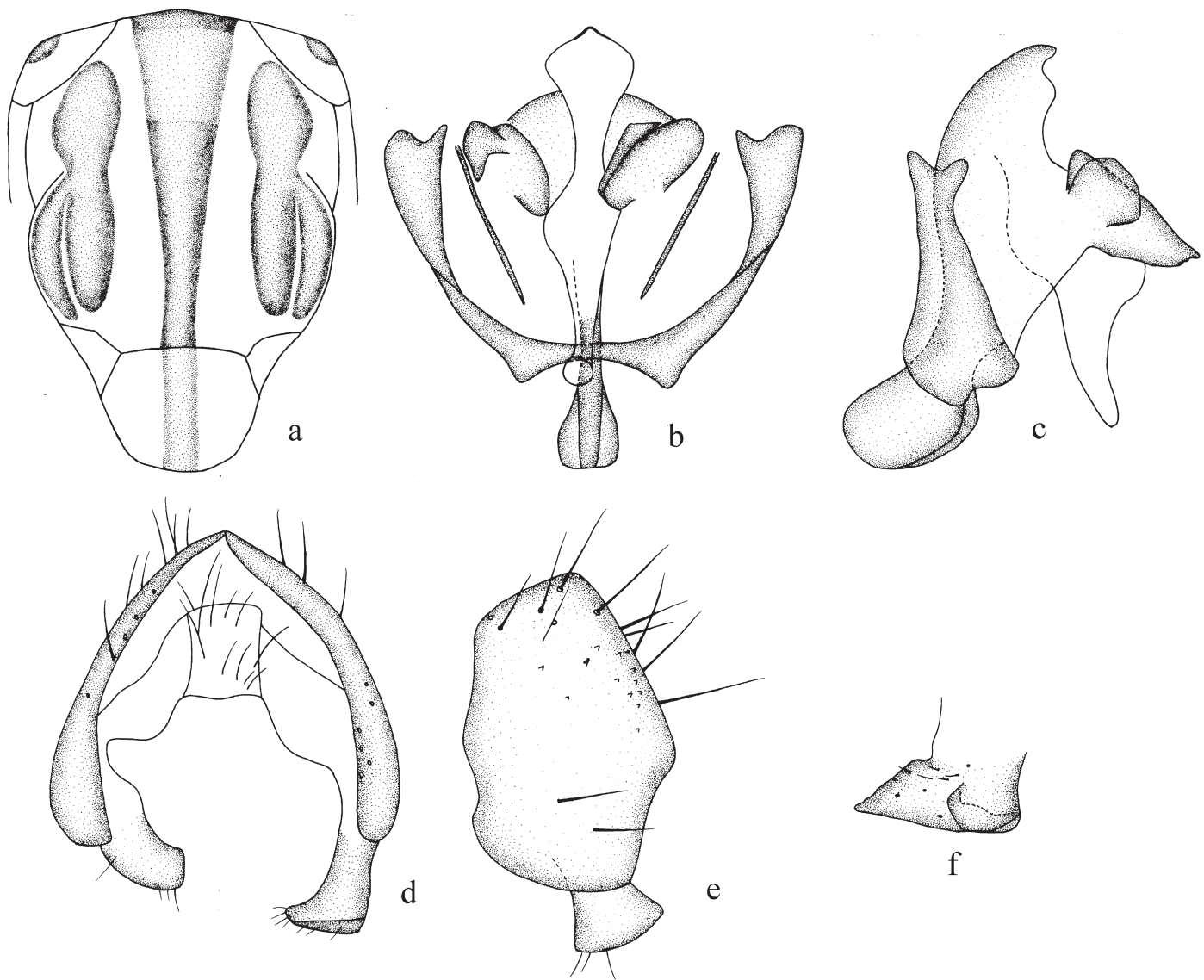

Fig. 2. Meromyza yangi sp. n., male. - a. Mesonotum, dorsal view. - b. Hypandrium and phallic complex, ventral view. - c. Hypandrium and phallic complex, lateral view. - d. Epandrium, posterior view. - e. Epandrium, lateral view. $-\mathrm{f}$. Gonite, lateral view.

Abdomen brownish yellow with pale pollen; each tergite with a black median stripe. Hairs pale.

Male genitalia (Fig. 2b-f). Epandrium yellow, 0.9 times as long as wide; surstylus long, about 1.5 times as long as wide; gonite black and stout, posterior gonite attached to anterior gonite at posterior portion. Hairs and bristles on epandrium short and black.

Female. Unknown.

Distribution. China (Inner Mongolia), Palaearctic Realm.

Remarks. The new species is similar to Meromyza pratorum Meigen, 1830 in the pale palpus and stout gonite, but can be separated from the latter by the yellow thoracic pleuron without any spots and epandrium with the short bristles. In $M$. pratorum, the thoracic pleuron has the brown spots, and the epandrium has the distinctly long bristles (Kanmiya 1978).

Etymology. The species is named after the collector, Prof. Jikun Yang.

\subsection{Meromyza zhuae sp. n. (Fig. 3)}

Material examined. Holotype ${ }^{\lambda}$ : Inner Mongolia: Xilin Gol Meng, 15.VIII.1978, Leg. JikunYang.

Diagnosis. Head yellow, occiput with black spot. Palpus pale. Mesonotum yellow with three entirely black stripes, median stripe extending to scutellum. Thoracic pleuron yellow with a small black spot on anepisternum, a large brownish spot on katepisternum. Anterior gonite stout.

Description. Male. Body length $3.1 \mathrm{~mm}$, wing length $2.5 \mathrm{~mm}$. 

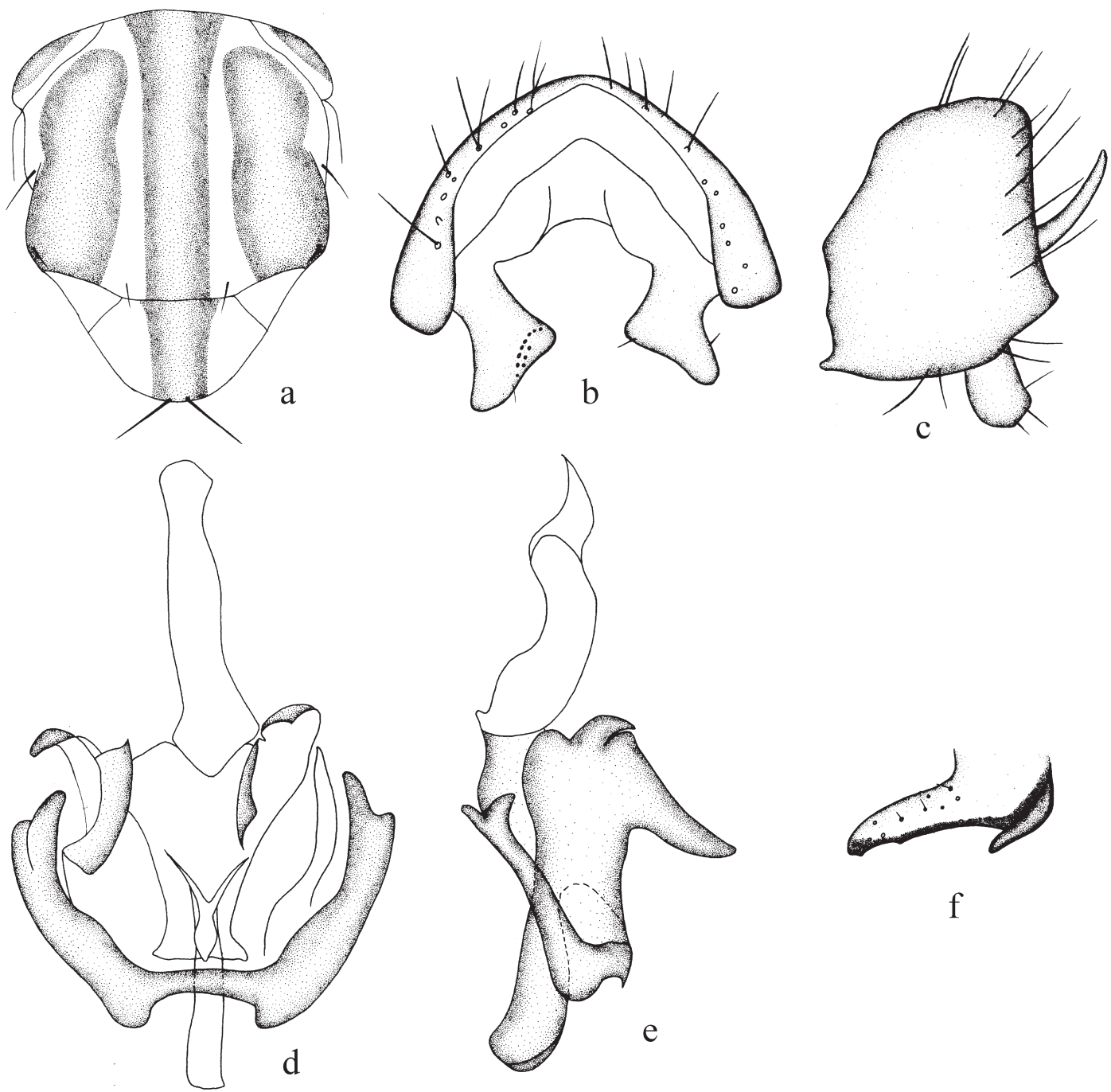

f

Fig. 3. Meromyza zhuae sp. n., male. - a. Mesonotum, dorsal view. - b. Epandrium, posterior view. - c. Epandrium, lateral view. - d. Hypandrium and phallic complex, ventral view. - e. Hypandrium and phallic complex, lateral view. - f. Gonite, lateral view.

Head yellow with pale pollen, about 1.2 times as wide as long, and 1.1 times as wide as mesonotum; ocellar triangle yellow with black ocellar tubercle, posterior portion of ocellar triangle black; occiput with a black spot, face without any spot. Hairs and bristles on head black except gena with pale hairs; in profile, head 1.1 times as long as high; gena 1.3 times as wide as third antennal segment; frons not distinctly produced beyond eye by about 0.3 times as long as long axis of eye. Antenna brown with pale pollen; third antennal segment dark brown on dorsal surface, and 1.3 times as long as wide; arista blackish brown with brown basal segment. Hairs on antenna pale. Proboscis brown with pale hairs; palpus pale with pale hairs.

Thorax (Fig.3a) yellow with pale pollen. Postpronotum with a black spot. Mesonotum 1.1 times as long as wide, with 3 entirely black stripes, median stripe extending to scutellum; thoracic pleuron yellow, with a small black spot on anepisternum, a large brownish spot on katepisternum; scutellum yellow with a black median stripe. Hairs and bristles on thorax black, but katepisternum with some long pale hairs. Wing 
hyaline, about 2.8 times as long as wide; veins brownish; relative length of costal section 2 nd: 3rd: 4th as 3: 3.2: 3. Halter yellow. Legs yellow with pale pollen. Hind femur 0.3 times as wide as long, and 1.5 times as wide as fore femur. Hairs and bristles on legs black and pale.

Abdomen blackish brown with pale pollen. Hairs pale.

Male genitalia (Fig. 3b-f). Epandrium yellow, 1.8 times as wide as long; surstylus widened apically; anterior gonite stout, posterior gonite curved and attached to posterior portion of anterior gonite.

Female. Unknown.

Distribution. China (Inner Mongolia), Palaearctic Realm.

Remarks. The new species is similar to Meromyza inornata Becker, 1910 in the pale palpus, widened surstylus and stout anterior gonite, but can be separated from the latter by the black median stripe on the mesonotum extending to the scutellum and black spot on the occiput. In $M$. inornata, the median stripe on the mesonotum is black and brown, not extending to the scutellum, the scutellum is entirely yellow, and the occiput is yellow (Kanmiya 1978).

Etymology. The species is named after Dr. Yajun Zhu in order to express our thanks for her help.

Acknowledgements. We are very grateful to Prof. Jikun Yang and Dr. Junhua Zhang, China Agricultural University, Beijing for collecting the specimens. This research was supported by the National Natural Science Foundation of China (No. 30225009).

\section{References}

An, S. \& Yang, D. 2005a: Notes on the species of the genus Meromyza Meigen, 1803 from Inner Mongolia (Diptera: Chloropidae). — Annales Zoologici 55(1): 77-82.

An, S. \& Yang, D. 2005b: Review of the genus Meromyza from China (Diptera: Chloropidae). — Entomologica Fennica 16(3): 151-158.

Andersson, H. 1977: Taxonomic and phylogenetic studies on Chloropidae (Diptera) with special reference to Old world genera. - Entomologica Scandinavica Supplementum 8: 200 pp.

Kanmiya, K. 1978: Revision of the genus Meromyza MG. (Diptera: Chloropidae) in Japan, with three newly recorded species. - Applied Entomology and Zoology 13 (4): 231-242.

Kanmiya, K. 1983: A systematic study of the Japanese Chloropidae (Diptera). - Memoirs of the Entomological Society of Washington 11: $370 \mathrm{pp}$.

Nartshuk, E. P. 1984: Family Chloropidae. — In: Soós, Á. \& Papp, L. (eds), Catalogue of Palaearctic Diptera 10: 222-299. Akademiai Kiado, Budapest. 402 pp.

Nartshuk, E. P. 1992: Revision of the species of Meromyza Meigen (Diptera, Chloropidae) from Finland. Entomologica Fennica 3: 121-138.

Nartshuk, E. P. 1994: New species and new records of Chloropidae from Afghanistan (Diptera). — Stobaeana 3 : $1-5$.

Sabrosky, C. W. 1980: Family Chloropidae. - In: Crosskey, R. W. (ed.), Catalogue of the Diptera of the Afrotropical Region: 695-712. British Museum (Natural History), London. 1437 pp.

Sabrosky, C. W. 1984: 81. Family Chloropidae. — In: A catalogue of the Diptera of the Americas south of the United States. Museu de Zoologia, Universidade de São Paulo. 63 pp.

Sabrosky, C. W. 1987: Chloropidae. - In: McAlpine, J. F. et al. (coord.), Manual of Nearctic Diptera 2: 1049 1067. Research Branch Agricultural Canada Monograph No. 28: 675-1332. 